\title{
Correspondence
}

\section{Reprint Request Reflexes}

Sir,- I cannot entirely agree with Drs Davies, MeKenzie and Turner (Nature, May 30) that our spoof letters produced remarkably few reprint requests. My letter to you printed on May 30 was written on April 8 and the number of requests has now reached 111, while a few more come in each week. Requests for the original "middle article", the genuine one, came to 986 . If one assumes that this number included about 111 from people who had not read the article (probably an underestimate), then the ratio of "phoney" to "genuine" requests is at least 1 to 8 . This ratio varies considerably from country to country; the worst (highest) is from Germany at $16 / 36$, and Czechoslovakia $(9 / 28)$ where it may be difficult to get the journal. Other continental and Scandinavian countries are much better (14/148) and USA is slightly worse than average $(60 / 434)$. As one would expect, the ratio for UK and Commonwealth countries is low (8/174), but from these countries came the largest number of jocular cards such as the one from a Dr Sidney Arbour-Bridge ... not included in the reckoning.

Yours faithfully,

\section{R. Pickles}

University College,

Cardiff.

\section{Deservingly Franked}

SIR,-I was intcrested to read the results of recent experiments on reprint request reflexes by Dr Pickles and by Dr Davies and his collaborators (Nature, May 30).

My own policy is to send reprints in the first place to friends and colleagues known to be working in the same field and to people requesting them by letter; to people in places I would like to visit; and, of course, to those whose cards bear a pretty stamp.

\section{Yours faithfully,}

\section{W. J. Marshati}

University College Hospital Medical School, University Street, London WC1.

\section{Not a Killjoy}

Sir,-- As the brutes who "pulled up by the roots" the "delicate flower" planted by Drs Davies, McKenzie, and Turner (Nature, 226, 881; 1970), we too regret the apparent failure of their plan to count and identify the corps of foolish reprint-requesters. Objectively, of course, they and Dr Pickles might have been right in ascribing this negative result to Dateline in Science's "gratuitous republication" of their original announcements of this intention, so we tried to visualize just how our 125,000 readers-only physicians in active practice, and all of them in the United States - could manage to "do [their] cause no good".

Somehow, the image was blurred: we couldn't imagine very many American physicians reading Dateline, suddenly recognizing the impending faux pas, and quickly instructing the nurse scanning Current Contents not to request that piece on prostaglandins. The population enacting this scenario seems rather limited.

Indeed, Sir, it occurs to us that, if the test failed, it was not because of our "withering blast of publicity" but because of the experimental "design". Assuming one thoughtless pest dispatched a postcard, it may be said that the test succeeded--but would Davies et al, and Pickles seriously contend that they could anticipate an optimum or maximum number of such respondents? How then can they claim that Dateline's report inhibited any significant portion of an indefinable group? Why then are they disappointed ?

Perhaps Turner and his fellow applied mathematicians at Cambridge will devise a workable programme that can really flush out malingerers who acquire reprints to avoid paying $4 s$ weekly; should they do so, we pledge to keep their experiment secret.

$$
\text { Yours faithfully, }
$$

Dateline in Science, Inc.,

\section{Nat Haleibsky}

575 Madison Avenue, New York, NY 10022, USA.

\section{Spin-off from Cancer Research}

SIR,--I would like to comment on your quotation (Nature, 225,$991 ; 1970$ ) from Science is God by David Horrobin.

Probably it is true that cancer will not be understood until more is known about fundamental processes going on inside the cell. But since the time of Claude Bernard the idea that toxic compounds are useful tools in the study of fundamental processes has often been proved true. To take only one well known example, toxic antibiotics have been widely used to investigate the mechanism of synthesis of macromolecules. Was it ever suggested that actinomycin or puromycin should not be studied until after the synthesis of nucleic acids and protein had been elucidated? Similarly with compounds causing cancer. It was work with carcinogens which led to the discovery of DNA repair enzymes in mammalian cells, and thus revealed the occurrence of unsuspected fundamental biochemical processes. Incidentally, the ingenuity of the experiments is evidence for the scientific ability as well as for the dedication of the scientists concerned.

To mention only one other aspect of the subject, the rate of progress in the study of biochemical events con. trolling differentiation has been very slow. If cancer is a disease of differentiation, study of how carcinogens cause a change in cell type may help to throw light on this process.

$$
\text { Yours faithfully, }
$$

VALDA M. CradDOCK

MRC Toxicology Unit,

Medical Research Council Laboratories,

Woodmansterne Road,

Carshalton, Surrey. 